\title{
Study on the Construction of Evaluation System for Urban and Rural Logistics Integration Development Level
}

\author{
Yanmei Zhang \\ Qingdao Huanghai University, Qingdao Shandong, 266427, China
}

Keywords: Urban and rural logistics integration, Level, Evaluation system.

\begin{abstract}
In view of the continuous improvement of China's economic development, the trade market in rural areas has produced great development potential. However, the construction of logistics facilities in rural areas is still relatively weak. So, in the country to speed up the development process of urban and rural integration, the creation of urban and rural logistics system has become extremely important. In order to make urban and rural logistics integration more effective, it should highlight the evaluation system construction, so as to better implement the goal of urban and rural logistics integration, to achieve regional economic sustainable development. This paper discusses the meaning and characteristics of urban and rural logistics integration, expounds the main methods of urban and rural logistics integration development evaluation, and puts forward the strategy of further perfecting the evaluation system of urban and rural logistics integration level.
\end{abstract}

\section{Introduction}

In recent years, the Party Central Committee has included urbanization in the important work system, and the promotion of urban and rural integration has become an important part of China's urbanization. To achieve the integration of urban and rural development, not only to promote the economic and cultural exchanges between urban and rural areas, but also to the use of logistics system construction, urban and rural resources to achieve the coordinated and stable development. With the continuous improvement of China's logistics system, has gradually realized the city development as the center, to point to bring a new situation, which requires the active construction of urban and rural logistics integration level of development evaluation system, in order to achieve a comprehensive urban and rural logistics Docking.

\section{The Meaning and Characteristics of Urban - rural Logistics Integration}

The essence of logistics integration is the process of logistics integration, which covers the production and transportation, logistics and distribution, so that the entire supply chain into one of the important whole, and effectively establish the entire process from production to marketing services The The use of logistics integration, enabling enterprises to better control the cost of the logistics industry. At the same time, it should also use the Internet information technology, logistics and information flow between the close integration, and in the following implementation of real-time monitoring, dedication to our customers better for excellent service. As for the integration of urban and rural logistics platform, some researchers think that urban and rural logistics integration between urban and rural areas is the integration of logistics resources and coordination, the use of urban and rural areas to create a unified logistics center, a strong drive to China's rural logistics industry, And for the region within the logistics integration to lay a good foundation.

In the urban and rural logistics platform operation also need to have the following characteristics: First, integration. The implementation of urban and rural logistics integration, which means to 
effectively break the dual economic system has been insisting, and to shorten the gap between urban and rural logistics, we can implement the resources of various regions. To be based on the equalization of infrastructure, etc., and continuously enhance the supplier's joint integration system, the implementation of the supply chain at all stages of convergence. Second, regional. Urban and rural logistics integration of another prominent feature and regional. Regional mainly refers to the integration of logistics in a region, and is generally a central city for its gathering point, and then the nearby towns to create a network structure, thus to meet their region And can take the initiative to achieve the current logistics and distribution process. Three is adaptive. Mainly refers to the integration of urban and rural logistics is also constantly improved to achieve the urban and rural developed logistics mechanism and rural underdeveloped logistics body to adapt to the process. Mutual adaptation process.Fourth is Openness,Openness refers to the integration of urban and rural logistics, although the regional characteristics, but the logistics system will be a regional unit, spread to the country, the formation of townships to small cities, small cities to large cities, large cities to the central city of open mode.

\section{The Main Method of Evaluating the Development Level of Urban and Rural Logistics Integration}

\section{Analytic Hierarchy Process}

Because the current assessment of urban and rural logistics for the lack of adequate quantitative indicators, which requires logistics experts in the field after the study based on their own experience and knowledge to qualitative judgments, and then use quantitative technology to convert it into quantitative Data, and the formation of mathematical models. This method can better solve the above problems. This method is systematized and hierarchically analyzed by combining qualitative and quantitative. The operation of the program is: first for the actual creation of the target layer, the standard layer and the decision-making program layer structure model. After that, in order to get the relative weights of the standards or the specific programs under a certain standard, the relative importance of this new scale should be actively introduced. The criteria are compared to form a comparison matrix, and the vector of the comparison matrix is obtained, and the value is the weight occupied by each standard index. According to the consistency test, the standard feature vector of the comparison matrix and the eigenvector based on the single standard scheme are obtained respectively, and the weights of each specific scheme are calculated. After comparing the weights, Excellent program.

\section{Evaluation method}

First, to create an evaluation system. According to the framework of the evaluation system of urban and rural logistics integration in a certain region, and combining with the current situation of the logistics industry in the region, it is concluded that the logistics urban and rural integration standard and the specific indicators are among the assessment areas. The goal of this system is to create an integrated urban and rural logistics system. In the standard layer should be studied in the following four aspects, namely, the integration of the logistics industry planning, the integration of Internet construction, infrastructure equipment integration and third-party logistics. The first integration is the integration of urban and rural logistics should be fully integrated with the local economic development, industrial structure and detailed planning to introduce the integration of urban and rural logistics strategy; second integration is the actual situation of urban and rural logistics network nodes; Three integration is the road, railway facilities and Internet + logistics use of the situation reflected; the fourth integration refers to the policy from the full support of third-party logistics to the corresponding development, which will certainly promote the urban and rural logistics Integration plays a very positive role. Second, to analyze the indicators. The comparison matrix is created for the standard layer and the indicator layer, and the consistency is checked. Can be used MCE v1.0 software which AHP analysis of the implementation of a comprehensive calculation, the program 
uses the root method to calculate the weight of each layer. The third is to implement expert ratings. You can arrange experts to study A, B, C and other three places, and then use the Delphi method to collect and feedback the views of experts, and for the specific indicators to arrive at the comparison matrix, and verify its consistency. Four is to make the overall evaluation. By calculating the weight of the three places in the decision-making level, and the implementation of the comprehensive ranking, it is concluded that one of the highest levels of urban and rural logistics integration is the highest.

\section{Factor Analysis}

First, the choice of indicators. The evaluation of the logistics capacity of a certain area is not only achieved by a few indicators, it is necessary to integrate the index system to implement a comprehensive evaluation. However, because the current domestic and foreign research has not yet established a standardized logistics evaluation system. Regional logistics level can directly reflect the development of logistics in the region, can more objectively reflect the region's logistics industry development level. The indicators under the logistics industry output value, the number of logistics industry practitioners, logistics and freight turnover and other four secondary indicators. The construction of transportation infrastructure is an important foundation for the development of the logistics industry. The quality and quantity of the transportation industry will directly determine the capacity of the logistics operation. The total number of vehicles, the total mileage of the road, the total mileage of the railway and the total number of routes Level indicators. The level of information technology in the logistics industry covers the total number of Internet users and the total number of users and other two secondary indicators, the value of the logistics will determine the speed and fluency. A region of the logistics development environment will directly determine the potential after the development of logistics, logistics industry in the service industry, its development to a considerable extent to rely on external environment. The secondary environment of a region's logistics development environment covers the total retail sales of social consumer goods, fiscal revenue, fixed asset investment, total exports and the total population and other indicators. The above indicators cover the development of the logistics industry in many aspects, to fully reflect the environment for the development of the logistics industry has a supporting role. Second, the choice of evaluation methods. Because the number of indicators involved is more, so the introduction of factor analysis. The method is to convert many of the indexing systems into a few synthetic variables in order to find the implied relationship between variables. The final purpose of this method is to extract the common factors and calculate the target score, followed by a combination of indicators to determine a region in the urban and rural logistics integration of the actual situation. Third, for empirical analysis. Using Spss19.0 software to operate, after the entry of the original data, and then select the appropriate factor for analysis, the computer will automatically achieve the standardization of the original data, thus eliminating the specific indicators of the impact of the dimension. The factor contribution of the factor should be regarded as the weight of the factor score, so the choice of weight will be able to avoid the interference of human factors, so that the choice of weight has a stronger objectivity, the final score can also exclude human interference. The weight of the premise of the calculation of different regions have the weighted total score, which can be ranked on the city and county, the higher the score means that the logistics development of the better.

\section{Further improve the urban and rural logistics integration development level evaluation system construction strategy}

\section{The introduction of urban and rural logistics integration development plan}

To actively carry out pre-research, for the introduction of urban and rural integration of logistics development planning, and effectively play the urban logistics for rural logistics has the role of radiation and promote the role. To truly rural logistics development system included in the overall planning of China's logistics industry development, from the macro, the overall height of the introduction of a systematic urban and rural logistics integration planning, more rational distribution 
of logistics system. In this process, the government should continue to strengthen the comprehensive planning and comprehensive coordination role, the implementation of government intervention policy. To set up by the reform and other relevant government departments constructed by the joint meeting mechanism, a comprehensive coordination of China's urban and rural logistics management system. According to the principle of gradual and local conditions, and actively promote the integration of urban and rural logistics construction process.

\section{Expand the scale of supply and marketing cooperatives and agricultural leading enterprises}

Nowadays, the vast majority of rural circulation in our country is in a fragmented state, which makes it necessary for the supply and marketing cooperatives or agricultural leading enterprises to conduct a comprehensive organization with a view to achieving large-scale benefits. Therefore, by increasing the total number of supply and marketing cooperatives, Smooth flow of the way. After research, we can see that China's agricultural leading enterprises in the integration of urban and rural logistics development has a very important role. Therefore, by increasing the total number of agricultural leading enterprises, to expand its scale, and effectively narrow the distance between urban and rural logistics, and actively explore the agricultural leading enterprises + grass-roots farmers, agricultural enterprises + supply and marketing cooperatives + farmers and supply and marketing cooperatives + Farmers "and other ways to promote the integration of urban and rural logistics.

\section{And effectively increase the financial support for the rural logistics industry}

At present, China's investment in the rural logistics industry is much lower than that of the urban logistics industry. Therefore, in order to promote the integrated development of the urban and rural logistics industry, the financial sector must surely increase the investment in the logistics industry in rural areas, One of the important measures of urban nurturing rural areas. I think we should establish a specialized logistics fund, used to promote China's rural logistics industry to achieve new development. We should actively introduce the tax relief and other ways to operate in the rural areas of the logistics enterprises to the necessary policy support, so as to effectively change China's rural logistics companies in the current market economy, the tide of competition among the unfavorable factors. At the same time, should also actively encourage urban logistics companies to strengthen ties with rural counterparts to help them introduce the necessary facilities and technology.

\section{Improve the integration of urban and rural logistics platform construction}

To be committed to promoting the integration of urban and rural logistics information. In view of a considerable part of China's information construction is lagging behind, and the availability of information is also the gap between China's urban and rural logistics industry. Specific performance: China's urban areas of logistics infrastructure equipment is quite perfect, the degree of information is also very high, but the rural areas of the network penetration is quite low, but also the lack of sufficient accuracy. Because the information asymmetry, leading to our peasant masses is difficult to get the city needs all kinds of agricultural information, so that the peasant masses suffered a loss of undue, and urban logistics enterprises is by virtue of experience to obtain the necessary means of production, So as to increase the cost, leading to the emergence of a vicious cycle. Therefore, to further improve the logistics infrastructure in rural areas to create the work of the formation of urban and rural integration of logistics information platform, which effectively between urban and rural areas in the information asymmetry, promote the integration of urban and rural logistics platform.

\section{Conclusions}

In summary, the integration of urban and rural logistics application of modern logistics technology and its concept of urban and rural areas and other two major logistics system to implement a unified planning and integration of urban and rural areas with the synergistic effect of logistics to improve the integration of urban and rural logistics development level evaluation system. I think, urban and rural logistics integration level of development evaluation should be based on local conditions to develop a 
reasonable index and weight. In today's urban and rural logistics development is still the primary stage of the planning program is very important, so we should continue to promote the integration of urban and rural logistics development level evaluation system to promote China's urban and rural logistics industry to achieve new development.

\section{References}

[1] [1]Wang Zhongwei, Zhang Xueyan. Discussion on the Strategic Path of Logistics Integration in Urban and Rural Areas with Non - zero Starting Point, Business age, 2010(17).

[2] [2]Zhong Ling. Urban and Rural Logistics System Construction in the Process of Urban and Rural Integration,Business age, 2012(22).

[3] [3]Ding Junyou. Urban and Rural Economic Integration and Logistics Development, China Business and Market, 2011(8).

[4] [4]Nie Jialing, Shen Jin. The Construction of Urban and Rural Logistics Integration System in North, Logistics Engineering and Management, 2012(12).

[5] [5]Zhou Lingyun. Construction of Jiangsu 's Urban and Rural Logistics Integration System Oriented to Urban and Rural Two - way Circulation, Modern Management Science, 2013(7). 